\title{
Construction of a Butterfly Web Bridge
}

\author{
Kenichiro Ashizuka ${ }^{1}$, Kenji Miyamoto ${ }^{1}$, Kenichi Kata ${ }^{2}$ and Akio Kasuga ${ }^{2}$ \\ 1. Kyushu Branch Office, West Nippon Expressway Co., Ltd., Fukuoka 810-0001, Japan \\ 2. Civil Engineering Design Department, Sumitomo Mitsui Construction Co., Ltd., Tokyo 104-0051, Japan
}

\begin{abstract}
A new type of bridge called "butterfly web bridge" is under construction in Japan. In a butterfly web bridge, the butterfly-shaped web forms a structure that exhibits behavior similar to a double Warren truss. The $80 \mathrm{MPa}$ concrete is used for the butterfly web which has a precast plate with a thickness of $150 \mathrm{~mm}$. As butterfly web is a concrete material, reinforcement provided by prestressing tendons is needed on the tension side. Moreover, the $150 \mathrm{~mm}$ plate has no re-bars but is reinforced by steel fibers. This bridge, named Takubogawa Bridge, is a highway bridge and has 10 spans including the $87.5 \mathrm{~m}$ maximum span length. Takubogawa Bridge is constructed by free cantilevering method. The butterfly web enables the construction speed of cantilevering to be advanced about 50\% compared with conventional cast-in-situ method and can meet the requirement of light weight and low maintenance.
\end{abstract}

Key words: Precast plate, fibre reinforced concrete, construction speed, low maintenance.

\section{Introduction}

It is important to reduce the superstructure weight in the earthquake prone country and corrugated steel web bridges have been applied in many projects in Japan. However, maintenance cost should be needed to keep durability of the structure. Therefore, a new type of structure called "butterfly web" is developed. The Takubogawa Bridge is the world's first to use a butterfly web structure [1, 2] with butterfly-shaped concrete panels utilized in the web of the main girder as a means for erecting the bridge more efficiently and for reducing construction cost. The butterfly web structure uses butterfly-shaped panels, like those shown in Fig. 1, in the web. With respect to shear force acting on the web, it behaves similarly to a double Warren truss structure. The material for the components of the web is concrete and tensile stress areas are reinforced with prestressing single steel.

\section{Design of Butterfly Web}

\subsection{Bridge Outlines}

Takubogawa Bridge (Figs. 2 and 3) is located in the

Corresponding author: Kenichi Kata, section chief, research field: bridge engineering. E-mail: k-kata@smcon.co.jp. city of Hyuga, Miyazaki, Japan and forms part of the Higashi-Kyushu Expressway. The outline and general view of structure for the bridge are given below:

- structural type: 10-span continuous prestressed concrete butterfly web bridge;

- length: $712.5 \mathrm{~m}$;

- span lengths: $58.6 \mathrm{~m}+87.5 \mathrm{~m}+7 \times 73.5 \mathrm{~m}+$ $49.2 \mathrm{~m}$;

- effective width: $9.5 \mathrm{~m}$ to $9.7 \mathrm{~m}$.

\subsection{Construction Material Used}

The butterfly web comprises precast panels fabricated off-site at a plant using high strength fibre reinforced concrete with specified design strength of $80 \mathrm{MPa}$. Steel fibres of diameter $0.2 \mathrm{~mm}$ and length $22 \mathrm{~mm}$ are used to enhance shear capacity. Inside the panels prestressing steel members are placed to align with the orientation of tension acting on the panels. Prestressing is used as the method of pretensioning. The prestressing steel components are $15.2 \mathrm{~mm}$ diameter strands with embossed surfaces to enhance the adhesion of concrete. There is no reinforcing steel, which makes the panels easy to work with and makes maintenance easy. 


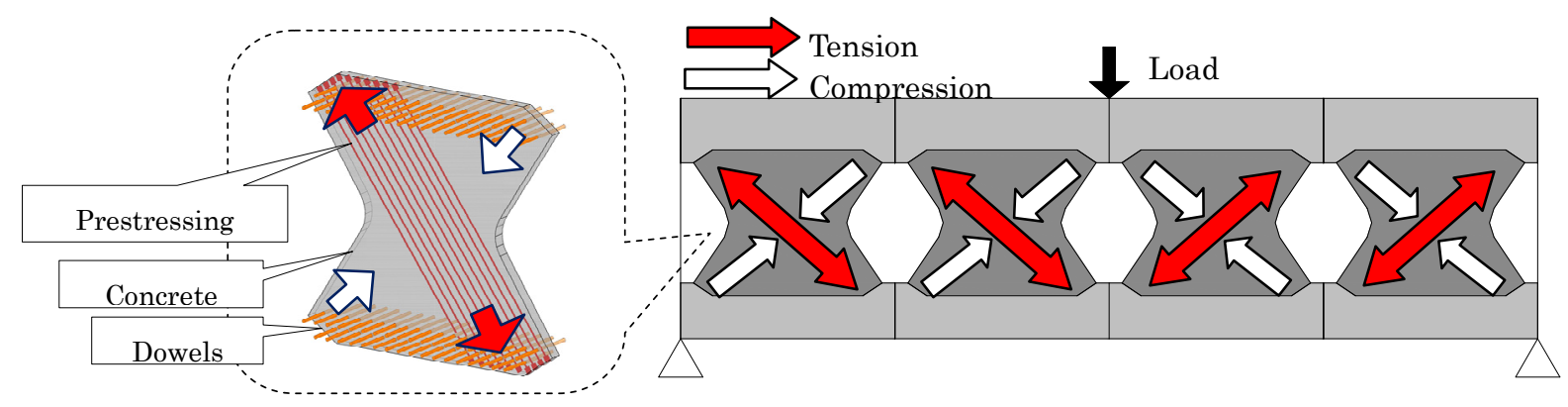

Fig. 1 Behaviour of butterfly web.

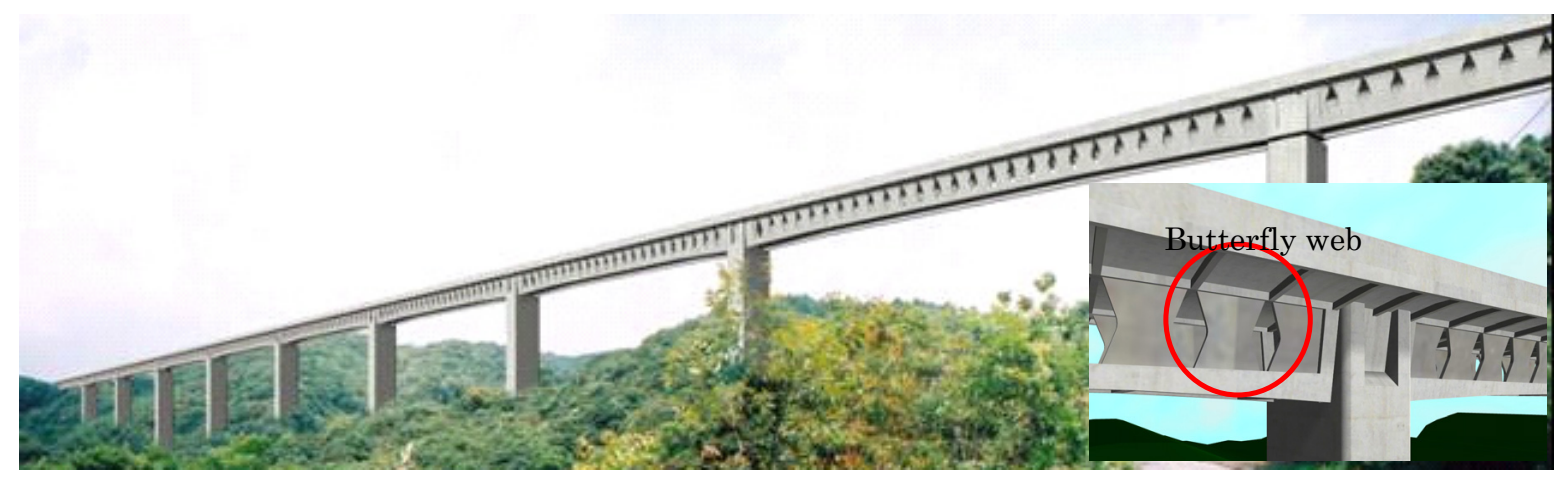

Fig. 2 Takubogawa Bridge.

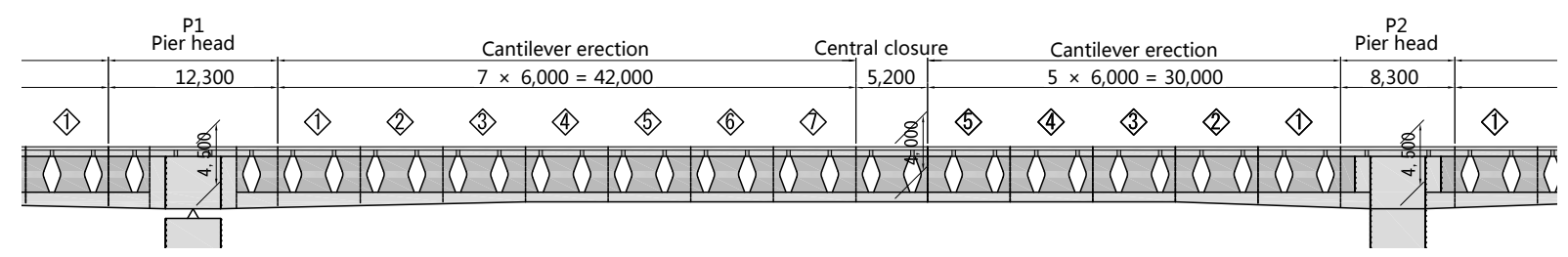

Fig. 3 General view of the bridge (units: $\mathrm{mm}$ ).

\subsection{Design of Butterfly Web Panel}

Based on the main girder height and the size of the indentations that make the butterfly shape, the butterfly web panels were designed to be $2.9 \mathrm{~m}$ long and were installed at a $3.0 \mathrm{~m}$ pitch (Fig. 4). Main girder height varies between $4.0 \mathrm{~m}$ and $4.5 \mathrm{~m}$, but despite this variation, the panel size is kept constant over the whole bridge, reducing the portion of shear resisted by the web panels near the pier head. As described above, in terms of resistance to shear force, the behaviour of the butterfly web is similar to that of a double Warren truss. The area of tensile stress is reinforced by prestressing steel, with the amount of steel determined such that there is no tensile stress intensity under dead load and no cracking occurs under design load. The structure is such that compressive force is resisted by the concrete. Web panel thickness is $150 \mathrm{~mm}$, a thickness designed to be sufficient for the necessary amount of prestressing steel as described above and to be able to resist the compressive force acting on the compression side under ultimate load. The panels incorporate dowels and steel reinforcements in order to join them to the upper and lower deck slabs. These elements are located within a $475 \mathrm{~mm}$ zone at the top and bottom of each panel designed to be embedded within the concrete deck slabs. Testing has confirmed that sufficient length is embedded for the stressing force of the pretensioning steel as described above to be effective in the panel.

A section of the main girder for the Takubogawa 


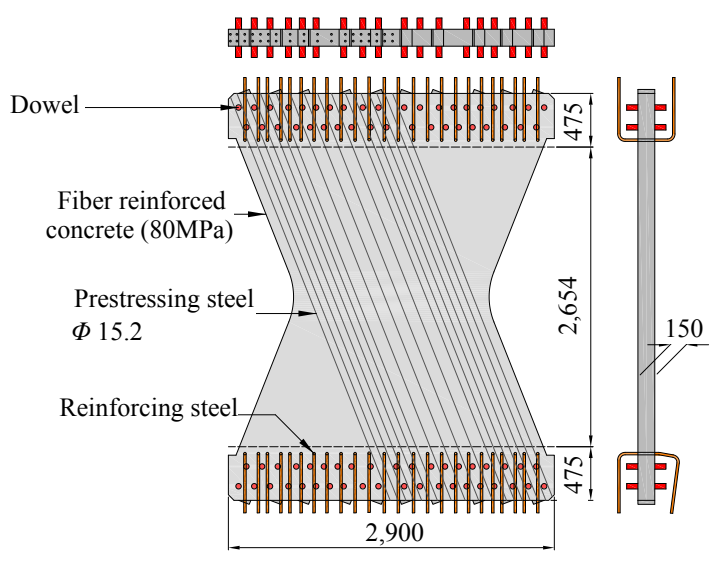

Fig. 4 Detail of the butterfly web (units: $\mathbf{m m}$ ).

Bridge is shown in Fig. 5. The butterfly web panels that comprise the web are discontinuous in the longitudinal direction of the bridge and the panels are relatively thin. This results in the web being less rigid than that of an ordinary concrete web with a box section. Consequently, greater bending unit stress occurs in the web due to dead weight and vehicle loads. For this reason, transverse reinforcing ribs are installed at $3.0 \mathrm{~m}$ pitch so as to become joints between the panels, suppressing web panel deformation and reducing stress intensity. As there is a discontinuous structure between the butterfly web panels, the transmission of stress intensity becomes complex. For this reason, testing and nonlinear analysis were performed in advance to confirm yield strength and ensure that the design would provide the prescribed shear capacity.

\section{Construction}

The cantilever construction used for the Takubogawa Bridge is shown in Figs. 6 and 7. Each butterfly web panel weighs approximately $3.25 \mathrm{t}$, enabling construction of a main girder lighter than would be possible with an ordinary concrete web. Consequently, a construction block length of $6.0 \mathrm{~m}$ could be used, equivalent to the length of two butterfly web panels on each side of the bridge. As a result, whereas constructing each span of this bridge with ordinary concrete box girder sections would have required eight blocks, the butterfly web enables construction with only five blocks. With fewer blocks required, the construction period can be substantially shortened. Also, since the butterfly web panels are not continuous in the longitudinal direction, there is no need for work to join adjacent web elements, which also enhance execution efficiency.

The butterfly web panels are fabricated at a plant situated $270 \mathrm{~km}$ away from the bridge construction

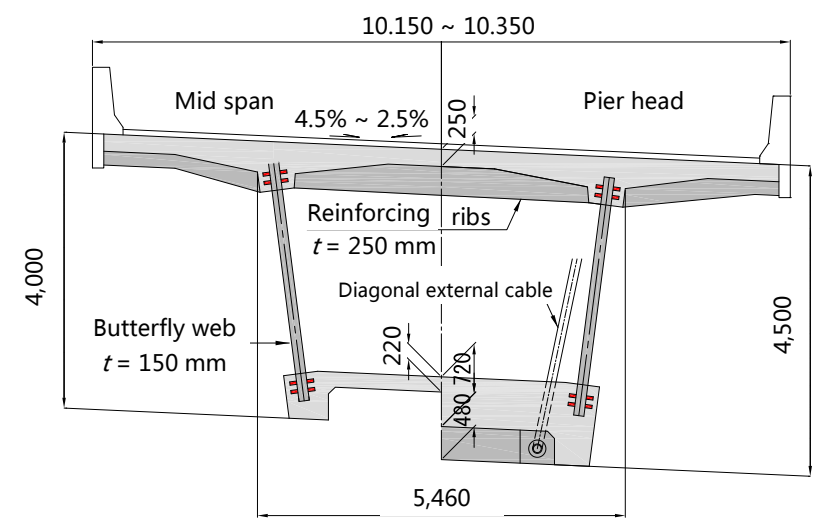

Fig. 5 Section of the main girder.

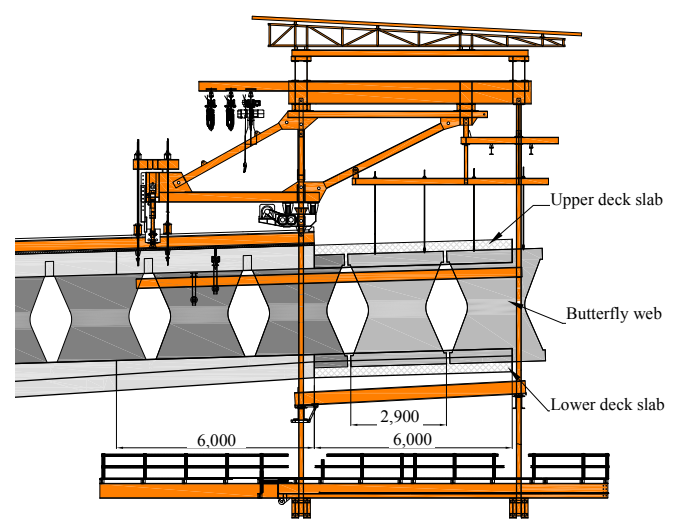

Fig. 6 Form traveler.

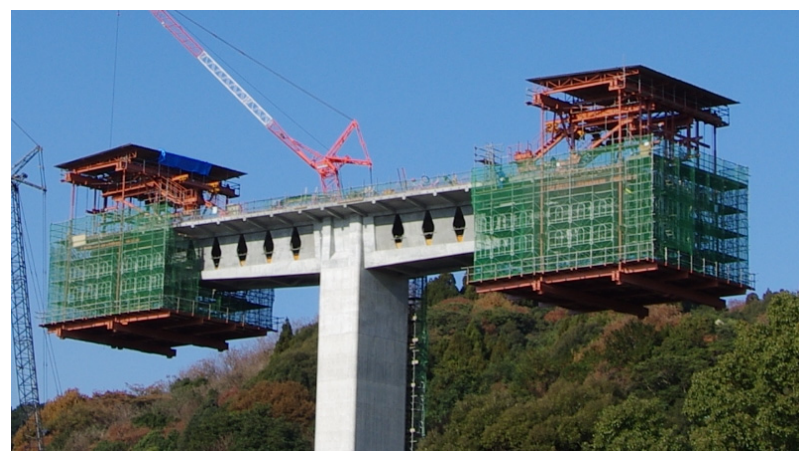

Fig. 7 Cantilever construction. 


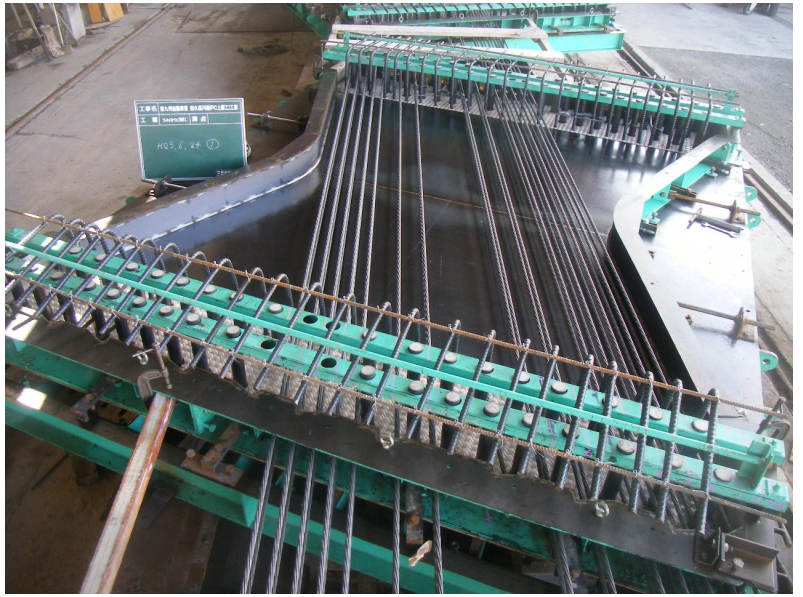

Fig. 8 Fabrication stage of panels.

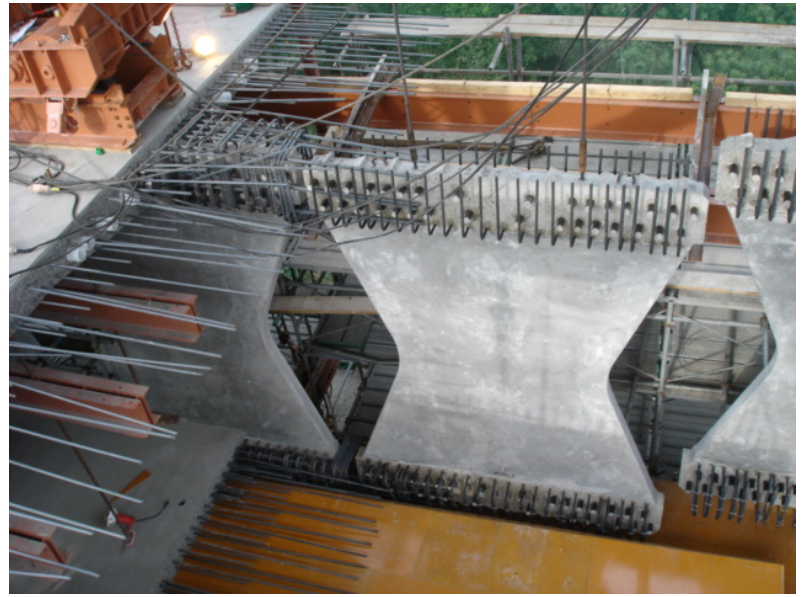

Fig. 9 Panels inside a form traveler.

Table $1 \quad \mathrm{CO}_{2}$ emissions (superstructure).

\begin{tabular}{|c|c|c|c|c|c|c|c|c|c|c|c|}
\hline & \multicolumn{2}{|c|}{ CON (cast-in-situ) } & \multicolumn{2}{|c|}{ CON (precast panel) } & \multicolumn{2}{|c|}{ Reinforcing steel } & \multicolumn{2}{|c|}{ Prestressing steel } & \multicolumn{3}{|c|}{ Total } \\
\hline & Volume & $\mathrm{CO}_{2}$ & Volume & $\mathrm{CO}_{2}$ & Quantity & $\mathrm{CO}_{2}$ & Quantity & $\mathrm{CO}_{2}$ & $\mathrm{CO}_{2}$ & Differenc & Ratio \\
\hline Box girder & $6,022 \mathrm{~m}^{3}$ & $1,770.5 \mathrm{t}$ & - & $0.0 \mathrm{t}$ & $1,247.8 \mathrm{t}$ & $957.1 \mathrm{t}$ & $287.3 \mathrm{t}$ & $379.8 \mathrm{t}$ & $3,107.4 \mathrm{t}$ & - & 1.00 \\
\hline Butter fly web & $5,021 \mathrm{~m}^{3}$ & $1,476.2 \mathrm{t}$ & $532 \mathrm{~m}^{3}$ & $234.1 \mathrm{t}$ & $1,177.5 \mathrm{t}$ & $903.2 \mathrm{t}$ & $232.8 \mathrm{t}$ & $307.8 \mathrm{t}$ & $2,921.2 \mathrm{t}$ & $-186.1 \mathrm{t}$ & 0.94 \\
\hline
\end{tabular}

site and transported to the site by truck. In total, the bridge requires 444 web panels (Fig. 8).

After transportation to the site, the panels are lifted to the bridge deck by crane and then moved to the cantilevered deck ends where the form travelers are located. Inside the form travelers, the panels are picked up and positioned as required (Fig. 9) and then the concrete for the upper and lower deck slabs is placed to construct the main girder.

\section{Ecological Effect}

Use of the butterfly web means that this bridge uses less concrete, reinforcing steel and prestressing steel for the main girder than an ordinary concrete box girder structure. Trial calculations made using the method set out in Ref. [3] indicate that the superstructure used for the bridge represents a $186 \mathrm{t}$ cut in $\mathrm{CO}_{2}$ emissions (Table 1).

\section{Conclusions}

In addition to enabling a lighter main girder, the butterfly web structure makes a substantial contribution to faster construction time due to advantages such as requiring a smaller number of construction block increments. Furthermore, maintenance is easier as the web panels do not use reinforcing steel and are high quality products produced in a plant using industrial fabrication processes. Consequently, this structure provides substantial reductions in both construction costs and maintenance costs.

\section{Acknowledgments}

The original source of this paper is the same title report of "fib Symposium Stockholm 2012" [4].

\section{References}

[1] A. Kasuga, K. Kata, K. Nakatsumi, Y. Takaki, New concept of composite bridges, in: Proceedings of 2 nd fib Congress, Naples, 2006, pp. 5-16.

[2] A. Kasuga, N. Nagamoto, K. Kata, H. Asai, Study of a bridge with a new structural system using ultra high strength fiber reinforced concrete, in: Proceedings of 3 nd fib Congress, Washington, 2010, p. 141.

[3] Recommendation on Environmental Performance Verification for Concrete Structures (Draft), JSCE (Japan Society of Civil Engineers) Concrete Library No. 125, 2005. (in Japanese)

[4] K. Ashizuka, K. Miyamoto, K. Kata, A. Kasuga, Construction of a butterfly web bridge, in: Proceedings of fib Symposium, Stockholm, 2012, pp. 545-548. 